\title{
The hemi-Mustard/bidirectional Glenn atrial switch procedure in the double-switch operation for congenitally corrected transposition of the great arteries: Rationale and midterm results
}

\author{
Sunil P. Malhotra, MD, ${ }^{\mathrm{a}}$ V. Mohan Reddy, MD, ${ }^{\mathrm{b}}$ Mary Qiu, BS, ${ }^{\mathrm{b}}$ Timothy J. Pirolli, MD, \\ Laura Barboza, BS, ${ }^{\mathrm{b}}$ Olaf Reinhartz, MD, ${ }^{\mathrm{b}}$ and Frank L. Hanley, $\mathrm{MD}^{\mathrm{b}}$
}

\begin{abstract}
Objective: This study was undertaken to assess the risks and benefits of the double-switch operation using a hemi-Mustard atrial switch procedure and the bidirectional Glenn operation for congenitally corrected transposition of the great arteries. To avoid complications associated with the complete Senning and Mustard procedures and to assist right-heart hemodynamics, we favor a modified atrial switch procedure, consisting of a hemi-Mustard procedure to baffle inferior vena caval return to the tricuspid valve in conjunction with a bidirectional Glenn operation.
\end{abstract}

\begin{abstract}
Methods: Between January 1994 and September 2009, anatomic repair was achieved in 48 patients. The Rastelli-atrial switch procedure was performed in 25 patients with pulmonary atresia and the arterial-atrial switch procedure was performed in 23 patients. A hemi-Mustard procedure was the atrial switch procedure for $70 \%$ (33/48) of anatomic repairs.

Results: There was 1 in-hospital death after anatomic repair. There were no late deaths or transplantation. At a median follow-up of 59.2 months, 43 of 47 survivors are in New York Heart Association class I. Bidirectional Glenn operation complications were uncommon (2/33), limited to the perioperative period, and seen in patients less than 4 months of age. Atrial baffle-related reoperations or sinus node dysfunction have not been observed. Tricuspid regurgitation decreased from a mean grade of 2.3 to 1.2 after repair $(P=.00002)$. Right ventriclepulmonary artery conduit longevity is significantly improved.
\end{abstract}

Conclusions: We describe a 15-year experience with the double-switch operation using a modified atrial switch procedure with favorable midterm results. The risks of the hemi-mustard and bidirectional Glenn operation are minimal and are limited to a well-defined patient subset. The benefits include prolonged conduit life, reduced baffle- and sinus node-related complications, and technical simplicity. (J Thorac Cardiovasc Surg 2011;141:162-70)

Surgical management of congenitally corrected transposition of the great arteries (ccTGA) has evolved from a physiologic repair that addresses structural lesions to an anatomic approach that supports the systemic circulation with the morphologic left ventricle (LV). Adoption of the double-switch operation has been driven by the dismal natural history of the systemic right ventricle (RV). Progressive functional impairment of the systemic RV has been observed in $40 \%$ at 3 years and $60 \%$ at 10 years after traditional repair. ${ }^{1,2}$ Successful early outcomes with anatomic repair were first reported by several centers in the mid-1990s. ${ }^{3-5}$

From the Congenital Heart Center, ${ }^{\text {a }}$ University of Florida, Gainesville, Fla; and the Department of Cardiothoracic Surgery, ${ }^{b}$ Stanford University, Stanford, Calif.

Disclosures: Authors have nothing to disclose with regard to commercial support.

Read at the 90th Annual Meeting of The American Association for Thoracic Surgery, Toronto, Ontario, Canada, May 1-5, 2010.

Received for publication May 4, 2010; revisions received Aug 3, 2010; accepted for publication Aug 29, 2010; available ahead of print Nov 9, 2010.

Address for reprints: Sunil P. Malhotra, MD, Department of Cardiothoracic Surgery, New York University Langone Medical Center, 530 First Ave, Suite 9V, New York, NY 10016 (E-mail: spmalhotramd@gmail.com).

0022-5223/\$36.00

Copyright (C) 2011 by The American Association for Thoracic Surgery doi:10.1016/j.jtcvs.2010.08.063
The anatomic variability observed in corrected transposition poses numerous technical challenges for anatomic repair. The surgical strategy must be tailored to account for associated cardiac lesions that are common in patients with ccTGA, such as ventricular septal defect (VSD), subpulmonary ventricular outflow tract obstruction or pulmonary atresia, and tricuspid valve dysplasia leading to incompetence of the systemic atrioventricular valve. Morphologic variables, including dextrocardia and atrial situs inversus, can greatly affect the visualization to create the atrial baffle.

It has been our preference to use a hemi-Mustard procedure that baffles the inferior caval return to the tricuspid valve in conjunction with a bidirectional Glenn (BDG) operation for the atrial switch component of the double-switch operation. Historical experience with the Mustard and Senning atrial switch procedures has identified a significant incidence of systemic venous and, to a lesser extent, pulmonary venous obstruction over the long-term..$^{6-8}$ Moreover, late development of sinus node dysfunction after the atrial switch procedure can be as high as $40 \%$ and is a risk factor for sudden death. ${ }^{7,9,10}$ The hemi-Mustard 


$$
\begin{aligned}
& \text { Abbreviations and Acronyms } \\
& \text { AAS = arterial-atrial switch } \\
& \text { BDG = bidirectional Glenn } \\
& \text { ccTGA }=\text { congenitally corrected transposition of } \\
& \text { the great arteries } \\
& \text { NYHA }=\text { New York Heart Association } \\
& \text { PA = pulmonary artery } \\
& \mathrm{PAB}=\text { pulmonary artery banding } \\
& \text { RAS = Rastelli-atrial switch } \\
& \mathrm{RV} \quad=\text { right ventricle } \\
& \mathrm{TR}=\text { tricuspid regurgitation } \\
& \text { VSD = ventricular septal defect }
\end{aligned}
$$

modification obviates the need for the superior caval suture lines and, as a result, might result in a reduced incidence of these late complications of traditional atrial baffle procedures. Use of the BDG operation also decreases the volume load on the failing RV and reduces strain on a dysplastic or Ebsteinoid tricuspid valve, providing potential benefits. The reduced volume load should be particularly beneficial in those patients receiving an RV-pulmonary artery (PA) conduit.

An added benefit of the hemi-Mustard procedure is the technical advantage afforded in cases in which adequate exposure for construction of the atrial baffle is limited, such as dextrocardia or situs inversus. The posterior displacement of the atrial chambers in the setting of these positional anomalies combined with the lack of volume loading of the atria due to the absence of an atrial septal defect compromise visualization to perform the conventional Mustard or Senning baffle procedure.

This study represents a 15-year experience with anatomic repair for all cases of ccTGA with 2 adequate ventricles. When possible, the hemi-Mustard/BDG modified atrial switch procedure was performed along with an arterial switch or Rastelli procedure. This study focuses particularly on assessing the risks and benefits of this particular technique. Patient selection, operative strategy, and midterm outcomes are presented.

\section{MATERIALS AND METHODS}

Between January 1994 and September 2009, 48 patients with ccTGA and 2 adequately sized ventricles underwent a surgical management strategy designed to place the morphologic LV in the systemic circulation (Figure 1). A retrospective review of patients' charts, the operative record, diagnostic reports, and outpatient clinic records was performed in accordance with an accepted protocol from the Stanford University Institutional Review Board. Individual patient consent was waived because of the retrospective nature of the study.

Diagnosis of ccTGA and delineation of cardiac anatomy was established by means of echocardiographic analysis in all cases. Echocardiographic analysis also was used to characterize systolic ventricular function and the severity of tricuspid regurgitation (TR). TR was clas- sified on a scale of 1 to 4 (1, trace; 2, mild; 3, moderate; and 4, severe).

Patient follow-up was obtained from records of the most recent pediatric cardiologist's examination and assessment. The most recent echocardiogram was obtained for assessment of ventricular function, valve function, and baffle leak or obstruction. Follow-up ranged from 7 months to 16 years, with a median follow-up of 4.9 years.

\section{Patients' Characteristics}

There was an equal distribution of male and female patients in this study ( 24 of each sex). The median age at anatomic repair was 3.0 years (range, 3.9 months -24.0 years). Ten patients were less than 1 year of age at time of the double-switch operation. The age distribution is depicted in Figure 2.

The most common associated cardiac defect was a VSD, which was present in 40 patients. Pulmonary atresia was present in 22 patients. Four of these patients had major aortopulmonary collateral arteries as the source of pulmonary blood flow. Severe subpulmonary obstruction resulting in functional pulmonary atresia was present in 3 patients. Seven patients had mild-to-moderate subpulmonary obstruction. Tricuspid valve abnormalities were present in 22 patients. In 10 patients the tricuspid valve had Ebsteinoid features. TR was at least moderate in 20 patients. Complete heart block requiring permanent pacing was present in 4 patients before anatomic repair.

Positional anomalies of the cardiac apex were common, occurring in $35 \%$ of patients in this series. Of the 48 patients undergoing the doubleswitch operation, dextrocardia with situs solitus was present in 10 $(20 \%)$, and dextrocardia with situs inversus was present in $6(13 \%)$. An additional patient had mesocardia with situs solitus.

\section{Surgical Strategy}

Anatomic correction for ccTGA was tailored to the patients' specific anatomies. Patients underwent one of 2 approaches to anatomic repair (1) an arterial-atrial switch (AAS) procedure if an appropriately sized pulmonary valve was present $(n=23)$ or (2) the Rastelli-atrial switch (RAS) procedure for patients with pulmonary atresia $(\mathrm{n}=22)$ or severe subpulmonary stenosis $(\mathrm{n}=3)$.

Surgical procedures performed before anatomic repair are displayed in Table 1. In the AAS group the majority of these procedures were designed to prepare the morphologic LV for the systemic afterload. Pulmonary artery banding (PAB) was performed in $17(74 \%)$ patients before the AAS procedure. Eight of these patients required $\mathrm{PAB}$ tightening before anatomic repair because of inadequate LV preparation. The suitability of the AAS procedure after PAB was determined based on echocardiographic evidence of normal LV and mitral valve function, cardiac catheterization evidence of near-systemic morphologic LV pressure and low end-diastolic pressure, and achievement of normal LV mass by means of magnetic resonance imaging.

Patients undergoing the RAS procedure because of pulmonary atresia typically required a systemic artery-PA shunt to provide a reliable source of pulmonary blood flow. A modified Blalock-Taussig shunt was performed in $17(68 \%)$ patients undergoing the RAS procedure. Of the 4 patients with pulmonary atresia and major aortopulmonary collateral arteries, 2 required an aortopulmonary window to promote growth of diffusely hypoplastic branch pulmonary arteries. All 4 patients ultimately underwent 1-stage unifocalization to a central aortopulmonary shunt before anatomic repair of ccTGA.

\section{Surgical Technique}

PAB. A midline sternotomy was performed to expose the aorta and PA Minimal dissection was performed to encircle the proximal main PA with a Silastic band (Dow Corning, Midland, Mich). The degree of band tightening was guided by simultaneous transesophageal echocardiographic analysis and direct proximal PA pressure measurement. As the band was 


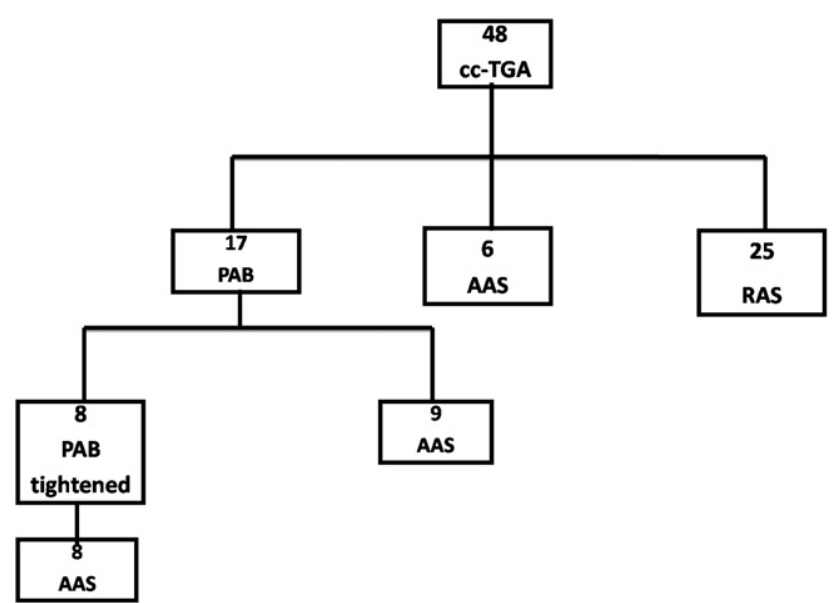

FIGURE 1. The surgical approach to anatomic repair in 48 patients. $c c T G A$, Congenitally corrected transposition of the great arteries; $P A B$, pulmonary artery banding; $A A S$, arterial-atrial switch; $R A S$, Rastelli-atrial switch.

tightened to achieve successively higher pressures, the LV was monitored for diminished systolic function. As the LV pressure increased, transesophageal echocardiographic analysis demonstrated shift of the intraventricular septum and decreased TR. The optimal post-PAB LV pressure of approximately $80 \%$ of systemic pressure was not obtained in every case because of LV dysfunction, requiring subsequent PA band tightening in 8 cases.

Anatomic repair. All patients underwent a median sternotomy and standard dissection in preparation for aortic and bicaval cannulation for cardiopulmonary bypass. Aortopulmonary shunts, if present, were dissected and ligated after initiation of cardiopulmonary bypass. Moderate hypothermia $\left(25^{\circ} \mathrm{C}-28^{\circ} \mathrm{C}\right)$ was used.

For the AAS procedure (Figure 3), the arterial switch procedure was performed first in standard fashion with coronary artery transfer and the Lecompte maneuver. If $\mathrm{PAB}$ was previously performed, this was taken down and served as the PA transection site. VSD closure was the most common additional procedure performed in this group (17/24). Concomitant procedures at the time of anatomic repair are listed in Table 2.

For the RAS procedure (Figure 4), a right ventriculotomy was performed, through which the LV to aortic tunnel was constructed. The Rastelli baffle was created with a Dacron patch, with care to avoid causing obstruction of either outflow tract. RV-PA continuity was then established by use of homograft valved conduit construction.

After the arterial switch or Rastelli procedures, the atrial baffle procedure was performed. The atrial switch procedure was a hemi-Mustard/ BDG operation in $33(70 \%)$ patients. The septum primum is resected completely, and if necessary, the limbus is cut in a superior direction to

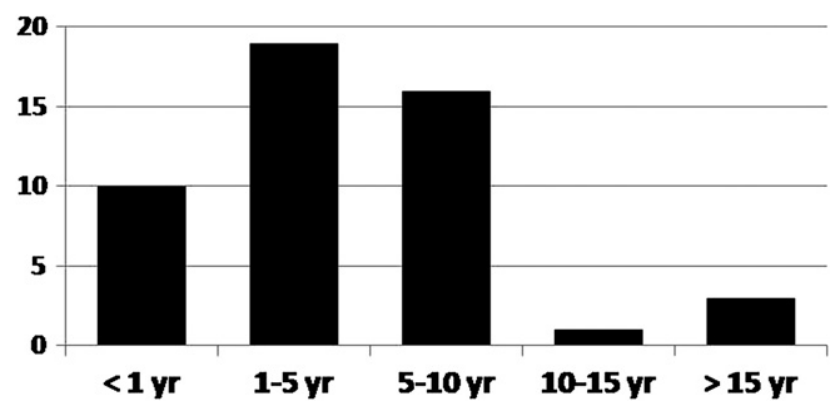

FIGURE 2. Age distribution of patients at the time of anatomic repair.
TABLE 1. Procedures performed before anatomic repair.

\begin{tabular}{lccc}
\hline \multicolumn{1}{c}{$\begin{array}{c}\text { Arterial-atrial switch } \\
\text { procedure group }\end{array}$} & \multicolumn{2}{c}{$\begin{array}{c}\text { Rastelli-atrial switch } \\
\text { procedure group }\end{array}$} & \\
\hline Pulmonary artery band & 17 & $\begin{array}{c}\text { Modified Blalock-Taussig } \\
\text { shunt }\end{array}$ & 17 \\
$\begin{array}{l}\text { Pulmonary artery band } \\
\text { tightening }\end{array}$ & 8 & $\begin{array}{c}\text { Second Modified Blalock- } \\
\text { Taussig shunt }\end{array}$ & 5 \\
Bidirectional Glenn operation & 2 & $\begin{array}{c}\text { Aortopulmonary window } \\
\text { before unifocalization }\end{array}$ & 2 \\
VSD repair & 1 & $\begin{array}{c}\text { Unifocalization of major } \\
\text { aortopulmonary collaterals }\end{array}$ & 4 \\
& & $\begin{array}{c}\text { to central shunt } \\
\text { Bidirectional Glenn operation } \\
\text { Pacemaker implantation }\end{array}$ & 5 \\
& Pacemaker implantation & 1 \\
\hline
\end{tabular}

VSD, Ventricular septal defect.

further enlarge the atrial septal opening. The polytetrafluoroethylene patch is always circular in shape. The diameter of the patch is the distance from the superior-most point of the tricuspid valve annulus to the inferior vena caval orifice. We also commonly cut into the coronary sinus because the transition from the right atrium to the left atrium (ie, traversing the atrial septum) has the greatest potential for baffle obstruction. Unroofing the coronary sinus provides more cross-sectional area within the baffle at this critical point. The BDG operation is then performed after removal of the aortic crossclamp. The azygous vein is typically ligated during the BDG operation.

A conventional Mustard baffle procedure was performed in $5(9 \%)$ patients, and the Senning procedure was performed in $10(21 \%)$ patients. The hemi-Mustard/BDG operation was avoided in cases in which a Glenn operation was contraindicated in the setting of increased pulmonary vascular resistance $(\mathrm{n}=5)$, for anatomic considerations when a single left superior vena cava drained to the coronary sinus $(n=2)$, and based on surgeon's preference $(n=8)$. Six of the cases in the latter category occurred in the first 2 years of the series as the approach was evolving.

\section{Statistical Analysis}

Statistical analysis was performed with Prism version 5.0 software (GraphPad Software, Inc, San Diego, Calif). Data are described as medians with ranges or means with standard deviations. Serial data are compared between groups by using Student's t test. Freedom from reoperation was determined by means of actuarial Kaplan-Meier analysis. Freedom from reoperation curves were compared with the Wilcoxon signed log-rank test.

\section{RESULTS}

\section{Mortality and Morbidity}

There was $1(2.1 \%)$ in-hospital death and no late deaths. The death occurred in a 68-kg, 9-year-old patient with ccTGA, pulmonary atresia, and dextrocardia who had previously undergone an modified Blalock-Taussig shunt, followed by a BDG operation. She underwent a Rastelli procedure with VSD enlargement, a hemi-Mustard procedure, and pacemaker placement. She exhibited a low cardiac output state postoperatively leading to progressive multisystem organ failure and ultimately died on postoperative day 32 .

Two patients required postoperative extracorporeal membrane oxygenation support. Both patients were successfully weaned from extracorporeal membrane oxygenation; 


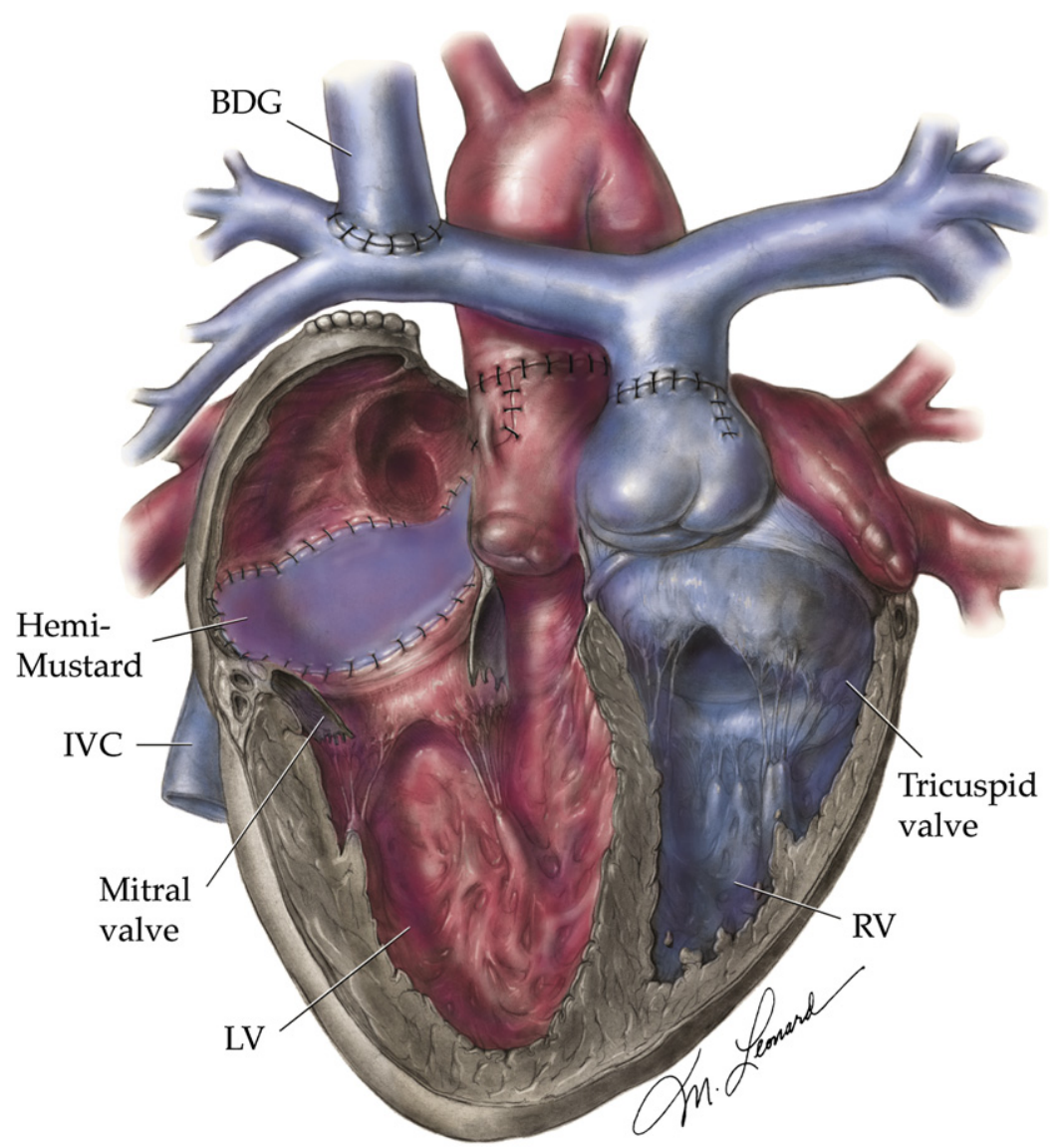

FIGURE 3. Illustration of the hemi-Mustard/bidirectional Glenn $(B D G)$ operation with the arterial-atrial switch procedure in a dextrorotated heart. $I V C$, Inferior vena cava; $L V$, left ventricle; $R V$, right ventricle.

however, 1 patient had hypoxic encephalopathy. Another patient had choreoathetosis in the early postoperative period. This was a 4-month-old patient who underwent a hemi-Mustard/BDG operation and likely had decreased cerebral perfusion pressure from the combination of systemic hypotension and increased BDG pressures on the first postoperative day.

The most common early complication was the development of complete heart block requiring implantation of a permanent pacing system. Four patients had pre-existing

TABLE 2. Concomitant procedures performed with anatomic repair

\begin{tabular}{llll}
\hline \multicolumn{1}{c}{$\begin{array}{c}\text { Arterial-atrial switch } \\
\text { procedure group }\end{array}$} & \multicolumn{2}{c}{$\begin{array}{c}\text { Rastelli-atrial switch } \\
\text { procedure group }\end{array}$} \\
\hline $\begin{array}{l}\text { Pulmonary artery band } \\
\text { takedown }\end{array}$ & 17 & $\begin{array}{c}\text { Takedown of aortopulmonary } \\
\text { shunt }\end{array}$ & 22 \\
VSD repair & 17 & $\begin{array}{l}\text { Pulmonary artery } \\
\text { reconstruction }\end{array}$ & 5 \\
Tricuspid valve repair & 4 & Tricuspid valve repair & 2 \\
$\begin{array}{l}\text { Relief of left ventricular } \\
\text { outflow tract obstruction }\end{array}$ & 2 & Pacemaker placement & 2 \\
Pulmonary artery & 2 & & \\
$\quad$ reconstruction & & & \\
\hline$V S D$, Ventricular septal defect. & & & \\
& & &
\end{tabular}

atrioventricular block requiring pacemaker implantation before anatomic repair. Complete heart block developed in the early postoperative period in $10(21 \%)$ patients. Pacemaker placement was performed at the time of the double-switch operation in 2 patients and before discharge in the remaining 8 patients. Late pacemaker placement was required in 2 additional patients at 22 months and 4 years after anatomic repair, respectively. Heart block was limited to those patients with situs solitus and l-looping. None of the 6 patients with situs inversus and d-looping experienced heart block, suggesting that the modified atrial baffle was not a factor in this complication.

\section{Reintervention}

Eleven $(23 \%)$ patients required 10 reoperations and 3 catheter-based interventions after anatomic repair (Table 3). Overall, freedom from reintervention at 1,5 , and 10 years was $86.4 \%, 83.8 \%$, and $71.8 \%$, respectively. Freedom from reintervention for the RAS and AAS groups at 5 years was $91.5 \%$ and $76.8 \%$, and at 10 years, it was $78.4 \%$ and $76.8 \%$ (Figure 5). Differences in freedom from reoperation for the 2 types of double-switch operations failed to reach statistical significance $(P=.09)$. 


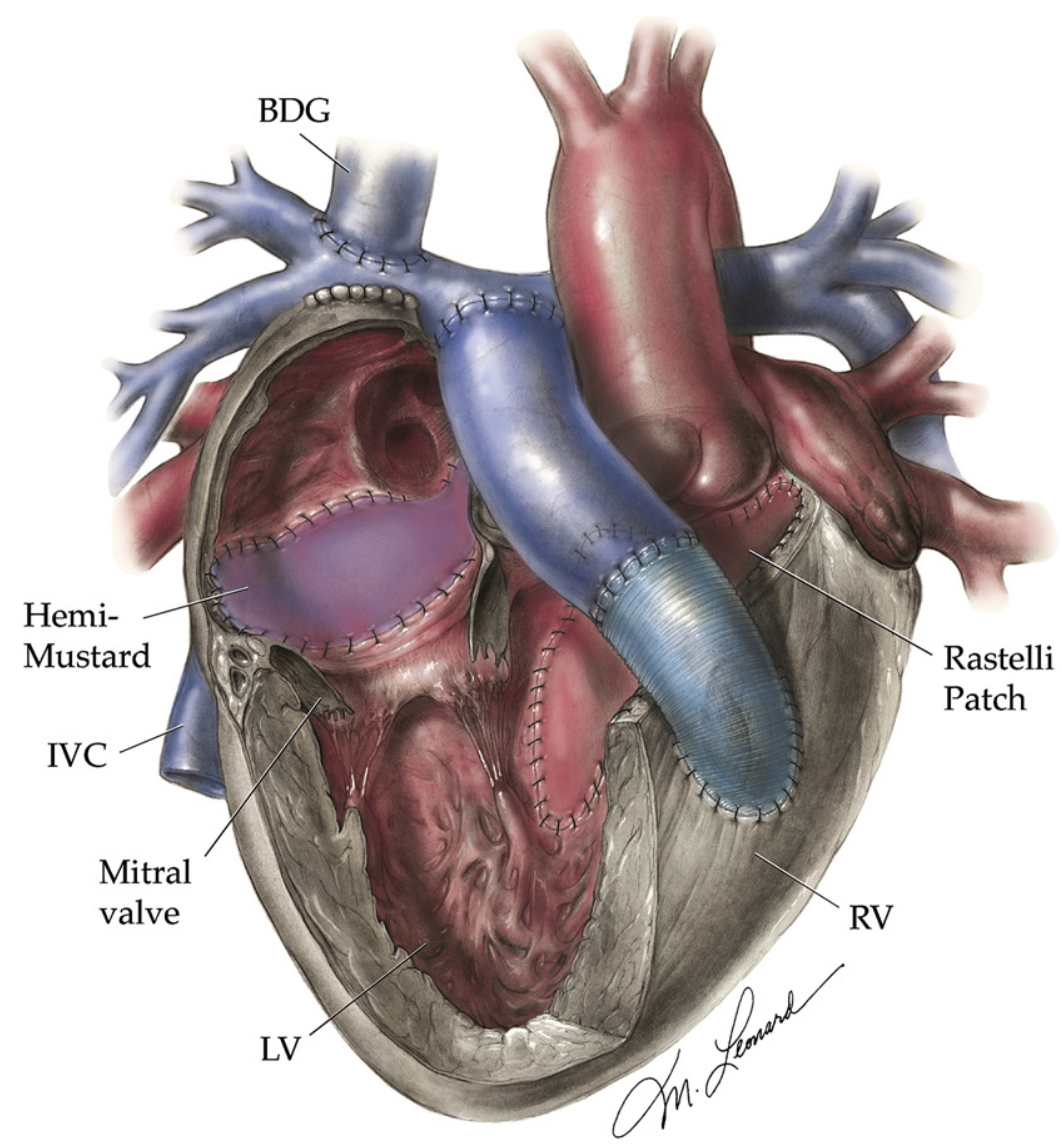

FIGURE 4. Illustration of hemi-Mustard/bidirectional Glenn $(B D G)$ operation with the Rastelli-atrial switch procedure in a dextrorotated heart. $I V C$, Inferior vena cava; $L V$, left ventricle; $R V$, right ventricle.

Reoperations in the AAS group occurred earlier than in the RAS group. Important reoperations in the AAS group included surgical revision of the coronary button after coronary occlusion in 2 patients and replacement of the neoaortic valve in 1 patient.

The most common reintervention in the RAS group was to address the RV-PA connection. The hemi-Mustard group had greater freedom from right ventricular outflow tract reoperation than patients who underwent a conventional atrial baffle procedure $(P=.019)$. There was $100 \%$ freedom from right ventricular outflow tract reintervention at

TABLE 3. Reinterventions after anatomic repair

\begin{tabular}{ll}
\hline \multicolumn{1}{c}{ Procedure } & 5 \\
\hline RVOT revision/conduit replacement & 1 \\
RVOT stent & 1 \\
Baffle leak device closure & 2 \\
Coronary artery revision & 1 \\
Mitral valve replacement & 1 \\
Aortic valve replacement & 1 \\
EP ablation for tachyarrhythmia & 1 \\
Takedown of bidirectional Glenn shunt &
\end{tabular}

$R V O T$, Right ventricular outflow tract; $E P$, electrophysiologic.
5 and 10 years in the patients undergoing the hemiMustard procedure compared with $75 \%$ at 5 years and $50 \%$ at 10 years in the patients who had a conventional Senning or Mustard procedure (Figure 6). To date, 2 patients in the RAS group who had a hemi-Mustard/BDG atrial switch procedure required revision of the RV-PA conduit at 11.6 and 12.4 years after anatomic repair, respectively.

There were 3 reinterventions specific to the atrial switch procedure performed. One patient who had a complete Senning procedure required a device closure of a baffle leak 3 months after the RAS. No patient with a hemiMustard/BDG operation has had a baffle leak or venous pathway obstruction. One patient undergoing the hemiMustard procedure had atrial tachyarrhythmias requiring ablation in the electrophysiology laboratory. Sinus node dysfunction has not been observed in the series. One patient with a hemi-Mustard/BDG operation required a takedown of the BDG shunt because of recurrent chylothorax. This was a 3.5-month-old patient with severe TR and increased pulmonary vascular resistance who had a circular shunt caused by a venovenous connection between the azygous vein and the inferior vena cava. 


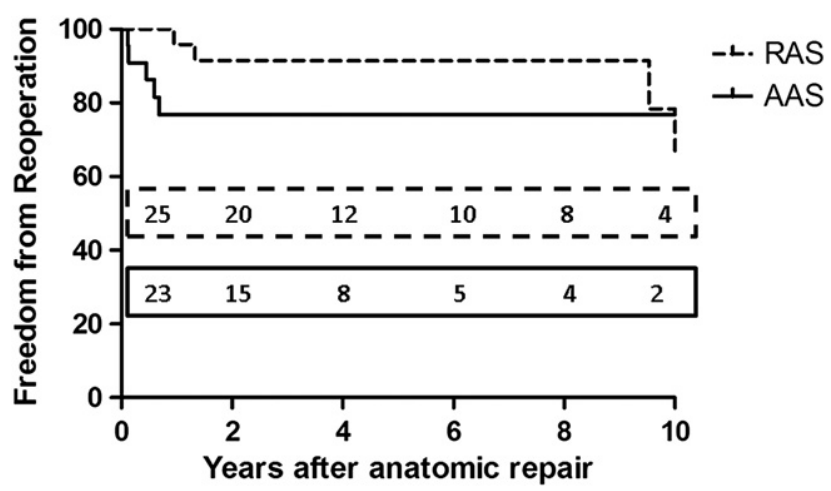

FIGURE 5. Freedom from reoperation in the Rastelli-atrial switch (RAS) and arterial-atrial switch $(A A S)$ procedures was not statistically different $(P=.09)$.

\section{Tricuspid Valve Function}

The mean TR echocardiographic grade before anatomic repair was $2.2 \pm 1.0$. Baseline TR was moderate or greater in $42 \%(20 / 48)$ of patients. After the double-switch operation, there was a significant decrease in the TR grade to $1.3 \pm 0.5$ ( $P=.00004$, Figure 7$)$. No patients have required tricuspid valve repair or replacement after anatomic repair.

\section{Aortic Valve Function}

To date, 2 (4\%) patients have experienced aortic regurgitation that was moderate or greater in severity. Both patients had undergone the AAS procedure. One of these patients, who had previously had a PA band placed for morphologic LV retraining, required mechanical aortic valve replacement.

\section{Functional Status}

At the most recent follow-up, 87\% of survivors had preserved LV systolic function. LV dysfunction was moderate in 4 patients and severe in 2 patients. Of these 6 patients, 2 are in New York Heart Association (NYHA) functional class I, 3 are in NYHA class II, and 1 is in NYHA class III. All 4 patients with functional heart failure underwent

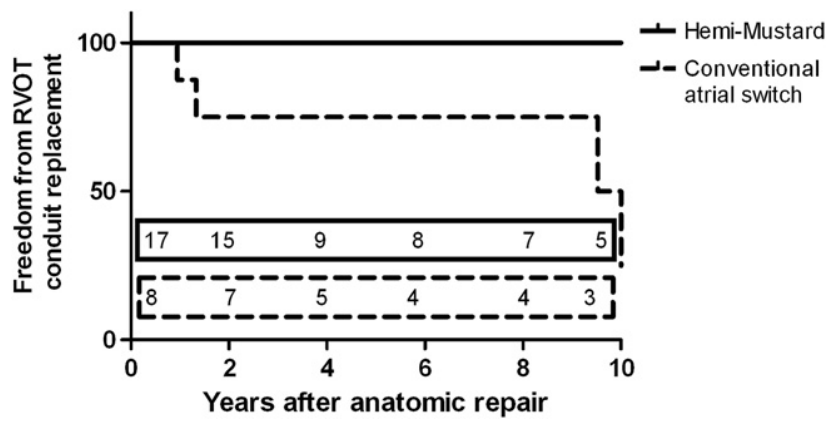

FIGURE 6. Freedom from reoperation on the right ventricular outflow tract (RVOT) was significantly greater in the hemi-Mustard group compared with that seen in the conventional atrial baffle group $(P=.019)$.

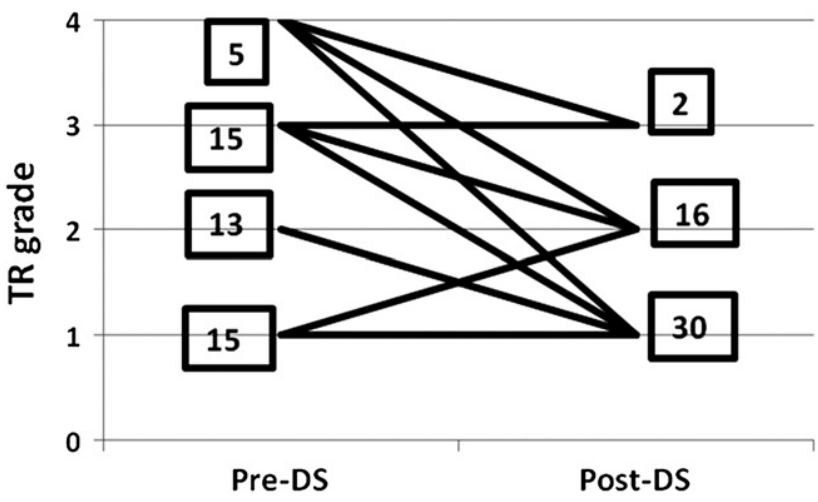

FIGURE 7. Tricuspid regurgitation (TR) grade decreased from $2.2 \pm 1.0$ to $1.3 \pm 0.5$ after the double-switch $(D S)$ procedure $(P=.00004)$.

the AAS procedure (Figure 8). These patients are undergoing medical management for heart failure, and no patient has required evaluation for heart transplantation. All patients were acyanotic at follow-up, with a mean oxygenation saturation of $97.7 \% \pm 2.0 \%$.

The AAS procedure carried an increased risk of diminished functional outcome when compared with the RAS procedure $(P=.013)$. However, patients undergoing the AAS procedure who required LV training before anatomic repair were not at increased risk of impaired cardiac function compared with patients undergoing the AAS procedure who did not require $\mathrm{PAB}(P=.13)$.

\section{DISCUSSION}

The use of the hemi-Mustard atrial baffle procedure in conjunction with a bidirectional Glenn in the anatomic repair of corrected transposition poses potential risks and benefits. This study demonstrates that the risk profile for this procedure is low. There is no increased mortality, either early or late, that can be attributable to either the baffle

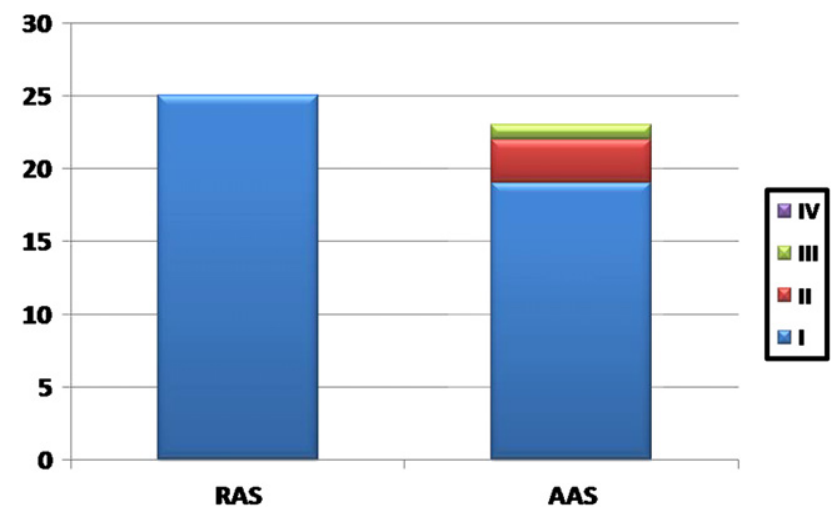

FIGURE 8. Functional status after anatomic repair. All patients undergoing the Rastelli-atrial switch (RAS) procedure were in New York Heart Association class I at follow-up. Impaired functional status was found in 4 patients undergoing the arterial-atrial switch $(A A S)$ procedure. 
patch or the BDG shunt. Limited morbidity (2/33 patients) was seen and was primarily related to the BDG operation rather than the simplified baffle procedure. We can now identify patients in whom complications related to the BDG operation are likely, and the procedure can be avoided in them. These include patients of any age with increased pulmonary vascular resistance and also very young patients ( $<4$ months of age) who require correction. The typical scenario for this latter situation would be the neonate or infant with severe systemic tricuspid valve regurgitation, a situation that demands early definitive intervention.

This study also demonstrates that there are multiple benefits of this procedure. The advantages of this choice of atrial switch procedure are 5-fold. First, in the RAS procedure, the volume across the RV-PA conduit is reduced, prolonging the life of the conduit. Second, the bidirectional Glenn reduces the volume load on the RV, which is often impaired at the time of repair. Third, reduction of the volume load on a dysplastic, often incompetent, tricuspid valve is advantageous. Moreover, long-term baffle complications, such as sinus node dysfunction or baffle obstruction, are much less likely with an IVC-tricuspid valve (hemi-Mustard) baffle procedure. The final advantage is the relative technical simplicity of the hemi-Mustard procedure compared with conventional atrial baffle procedures, which might be especially challenging when positional anomalies exist.

The midterm results from this experience suggest that these benefits might indeed be realized in patients undergoing the hemi-Mustard/BDG operation. NYHA functional class I was observed in more than $90 \%$ of patients who underwent the hemi-Mustard baffle procedure. Moreover, no patients have required consideration for heart transplantation, and there have been no late deaths. Recent series of anatomic repair for corrected transposition have reported $6 \%$ to $15 \%$ operative mortality and $7 \%$ late mortality rate. ${ }^{11-13}$

Our results demonstrate that TR decreased by approximately a whole grade after anatomic repair with a hemiMustard/BDG atrial switch procedure. The lower afterload of the pulmonary circulation likely contributes to improved tricuspid valve function after anatomic repair. Decreased TR has been observed in separate reports by Imamura and colleagues ${ }^{14}$ and Devaney and associates ${ }^{15}$ after anatomic repair. Unloading of the tricuspid valve resulting from the BDG operation might provide additional durability of tricuspid valve function over the longer term.

The hemi-Mustard procedure also eliminates the known long-term complications of the Senning and Mustard procedures. Long-term obstruction of the systemic venous pathway has been reported in the range of $10 \%$ to $15 \%{ }^{7,10}$ Recent series of anatomic repair have reported a 5\% to $7 \%$ rate of reintervention for baffle-related complications. ${ }^{12,16}$ More alarming is the long-term development of sinus node dysfunction related to the traditional atrial baffle procedures that have been reported in $35 \%$ to $46 \%$ of patients. ${ }^{9,17}$ Sharma and coworkers ${ }^{11}$ observed the late development of hemodynamically significant atrial dysrhythmias in 6 patients after anatomic repair; late deaths in 2 of these patients were attributed to uncontrolled atrial tachyarrhythmias.

Despite the high proportion of positional anomalies in this series $(35 \%)$, there were very few baffle-related complications. One patient with mesocardia who had a traditional Senning procedure had a baffle leak that required device closure. Our experience did not reveal a baffle leak or obstruction of the systemic or pulmonary venous pathways in the 33 patients who underwent a hemi-Mustard/ BDG operation. Moreover, sinus node dysfunction was not observed in any patient at follow-up.

Among the patients undergoing the Rastelli procedure, the hemi-Mustard/BDG operation conferred a distinct advantage in lifespan of the RV-PA conduit over that seen in patients who underwent conventional atrial switch procedures. Freedom from RV-PA conduit revision at 10 years was $100 \%$. Although conduit replacement is inevitable because of eventual homograft deterioration, the hemiMustard/BDG atrial switch procedure extends the longevity of the RV-PA conduit. Indeed, the first hemi-Mustard patient to require RV-PA conduit revision underwent RVPA conduit replacement 11.6 years after anatomic repair. The volume unloading of the RV that occurs with creation of the BDG shunt is likely responsible for the observed longevity of the RV-PA conduit in the patient undergoing the hemi-Mustard procedure.

Overall functional outcomes in patients undergoing the AAS procedure were diminished compared with those seen in the RAS group. However, the need for LV preparation for anatomic repair did not appear to be an increased risk factor for worse functional outcome. Complications from the LV training regimen were low, with only 1 patient requiring aortic valve replacement after anatomic repair for progressive aortic insufficiency.

The relatively high incidence of complete heart block in this cohort of patients most likely reflects the attenuated bundle of His in l-looped hearts. Heart block was present in 4 patients before anatomic repair, developed in 10 patients in the perioperative period, and occurred late in 2 patients. Interestingly, none of the 6 patients with situs inversus with d-looping had heart block. Although this was a small subset of patients, it does suggest that heart block was not due to a technical factor related to the hemi-Mustard suture line.

The limitations of the hemi-Mustard/BDG atrial switch procedure are related to the BDG component of the procedure. Increased pulmonary resistance can limit the use of the BDG operation. We have found that this occurs in 2 scenarios: (1) patients younger than 4 months with significant systemic TR and (2) any patient with increased pulmonary 
vascular resistance. The former was most likely the issue in both the patient who had choreoathetosis and the patient with the circular shunt. In these situations we will typically use a conventional Senning procedure. An additional drawback of the BDG operation for these patients is limited transvenous access for electrophysiologic studies and procedures.

We have described a widely applicable approach for anatomic repair of the entire spectrum of ccTGA. This 15-year experience demonstrates the utility of the hemi-Mustard/ BDG operation in most patients. Despite the multitude of challenges posed by the patient with corrected transposition, favorable early and midterm outcomes can be expected.

\section{References}

1. Sano T, Riesenfeld T, Karl TR, Wilkinson JL. Intermediate term outcome after intracardiac repair of associated cardiac defects in patients with atrioventricular and ventriculoarterial discordance. Circulation. 1995;92(suppl II):II272-8.

2. Hraska V, Duncan BW, Mayer JE Jr, Freed M, del Nido PJ, Jonas RA. Long-term outcome of surgically treated patients with corrected transposition of the great arteries. J Thorac Cardiovasc Surg. 2005;129:182-91.

3. Yagihara T, Kishimoto H, Isobe F, Yamamoto F, Nishigaki K, Matsuki O, et al. Double switch operation in cardiac anomalies with atrioventricular and ventriculoarterial discordance. J Thorac Cardiovasc Surg. 1994;107:351-8.

4. Reddy VM, McElhinney DB, Silverman NH, Hanley FL. The double switch procedure for anatomic repair of congenitally corrected transposition of the great arteries in infants and children. Eur Heart J. 1997;18:1470-7.

5. Karl TR, Weintraub RG, Brizard CP, Cochrane AD, Mee RB. Senning plus arterial switch operation for discordant (congenitally corrected) transposition. Ann Thorac Surg. 1997;64:495-502.

6. Clarkson PM, Neutze JM, Barratt-Boyce BG, Brandt PW. Late post-operative hemodynamic results and cine-angiocardiographic findings after Mustard atrial baffle repair for transposition of great arteries. Circulation. 1976;53:525.

7. Helbing WA, Hansen B, Ottenkamp J, Roemer J, Chin JG, Brom AG, et al. Longterm results of atrial correction for transposition of the great arteries: comparison of Mustard and Senning operations. J Thorac Cardiovasc Surg. 1994;108: 363-71.

8. Berman MA, Barash PS, Hellendbrand WE, Stansel HC Jr, Talner NS. Late development of severe pulmonary venous obstruction following the Mustard operation. Circulation. 1977;56(suppl II):II91-7.

9. Flinn CJ, Wolff GS, Dick M 2nd, Campbell RM, Borkat G, Casta A, et al. Cardiac rhythm after the Mustard operation for complete transposition of the great arteries. N Engl J Med. 1984;310:1635-42.

10. Williams WG, Trusler GA, Kirklin JW, Blackstone EH, Coles JG, Izukawa T, et al. Early and late results of a protocol for simple transposition leading to an atrial switch (Mustard) repair. J Thorac Cardiovasc Surg. 1988;95:717-23.

11. Sharma R, Talwar S, Marwah A, Shah S, Maheshwari S, Suresh P, et al. Anatomic repair for congenitally corrected transposition of the great arteries. J Thorac Cardiovasc Surg. 2009;137:404-12.

12. Langley SM, Winslaw DS, Stumper O, Dhillon R, de Giovanni JV, Wright JG, et al. Midterm results after restoration of the morphologically left ventricle to the systemic circulation in patients with congenitally corrected transposition of the great arteries. J Thorac Cardiovasc Surg. 2003;125:1229-41.

13. Brawn WJ, Barron DJ, Jones TJJ, Quinn DW. The fate of the retrained left ventricle after double switch procedure for congenitally corrected transposition of the great arteries. Semin Thorac Cardiovasc Surg Pediatr Card Surg Annu. 2003;69-73.

14. Imamura M, Drummond-Webb JJ, Murphy DJ, Prieto LR, Latson LA, Flamm SD, et al. Results of the double switch operation in the current era. Ann Thorac Surg. 2000;70:100-5.

15. Devaney EJ, Charpie JR, Ohye RG, Bove EL. Combined arterial switch and Senning operation for congenitally corrected transposition of the great arteries: patient selection and intermediate results. J Thorac Cardiovasc Surg. 2003; 125:500-7.

16. Ly M, Belli E, Leobon B, Kortas C, Grollmuss OE, Piot D, et al. Results of the double switch operation for corrected transposition of the great arteries. Eur J Cardiothorac Surg. 2009;35:879-84.
17. Dos L, Teruel L, Ferreira IJ, Rodriguez-Larrea J, Miro L, Girona J, Albert DC et al. Late outcome of Senning and Mustard procedures for corrected transposition of the great arteries. Heart. 2005;91:652-6.

\section{Discussion}

Dr David J. Barron (Birmingham, United Kingdom). Dr Malhotra, that was a very good presentation, very clear, and there is no doubt you have to be congratulated for what is an outstanding set of results on what is a very difficult group of patients to treat. You have set out a very clear rationale for what you see are the benefits of the 1.5-type repair.

My first question is, I would like to know just a little bit more about your strategy for pulmonary artery banding for training. Could you give us an idea of the age range of the patients that you're banding and particularly what the oldest patients are? But also, you've got 8 patients, I think, that have been banded but haven't yet had their definitive treatment. Are they all on a track for anatomical repair, or do you have some who failed banding?

Dr Malhotra. In terms of the banding protocol, the majority of the patients who were banded were under 10 years of age. There were a few teenagers who were also banded. We have a strict protocol in which patients are banded for at least a year and then studied using echo, catheter, and magnetic resonance imaging (MRI) to evaluate left ventricular (LV) function; with the catheter, we look at left ventricular end-diastolic pressure (LVEDP) less than 12 and LV pressure at least $90 \%$ of systemic pressure, and appropriate LV mass increase by MRI.

There were 8 patients who were banded previously who have not yet gone on to a double switch, 5 are awaiting improved function, 3 of them will likely stay at that stage because of LV dysfunction.

Dr Barron. What would be the destination for those patients, do you know?

Dr Malhotra. Medical management. They don't meet requirements for transplantation. They're still functional. But their LVs, for whatever reason, did not adequately prepare for a double switch.

Dr Barron. And I think that reflects most people's experiences, there is a small group of patients who will not train.

Dr Malhotra. Correct.

Dr Barron. Let me ask you about the Glenn. Can you just be clearer about how you assess the pulmonary vascular resistance and maybe what sort of superior vena cava (SVC) pressure you will tolerate at the end of the procedure?

Dr Malhotra. Yes, that's a good question. Even in the patients that had pulmonary atresia with major aortopulmonary collateral arteries, there were at least 2 of the 4 that had low enough pulmonary vascular resistance to allow a Glenn to be performed. And we knew that from the catheter data prior to double switch. Also, in terms of SVC pressure, typically we like to see the Glenn pressure under 12, sometimes we will tolerate up to $15 \mathrm{~mm} \mathrm{Hg}$.

Dr Barron. And you've had one patient in whom you've had to take down the Glenn relatively early. Are you seeing issues with prolonged pleural effusions and chylous effusions postoperatively with these patients?

Dr Malhotra. This patient certainly had prolonged chylous effusions, and we diligently studied the patient. And, in retrospect, 
this patient was very sick, was banded at another institution, was transferred to us at 2.5 months of age, and we went ahead and did the double switch with the Glenn. This patient had severe tricuspid regurgitation and was 3.5-months-old at the time of the double switch. We likely should have done a Senning in that case. This highlights some of the lessons we have learned from our experience.

Dr Barron. Now, you've cited very clear reasons why you feel there are benefits to the 1.5 repair in performing the Glenn and one of them you say is less risk of sinus node dysfunction. You've had one patient who has had evidence of sinus node dysfunction, and I think you've had a $20 \%$ incidence of heart block across the series, which isn't unusual, it's part of the underlying condition and also is a recognized high incidence after surgery; but what concerns me is that, if you've got a bidirectional Glenn, that really limits your options for pacing now and also pacing in the future, and you're committing these patients to epicardial systems and repeated surgeries. It seems to me the heart block is more of a concern than sinus node dysfunction.

Dr Malhotra. That's a very valid point. There were a few patients in the series that we knew were in heart block coming off bypass and we put a pacing system in prior to closure, but there are a few other patients who required a pacing system placed before they left the hospital and required a reoperation for that. And one of the drawbacks of this approach is that it limits the access for EP procedures, but we think the benefits certainly outweigh the downsides of that.

Dr Barron. I mean I think in defense of the Senning-and you've done Sennings or atrial switches in $30 \%$ of these patients and not had too much morbidity from the sound of it-a lot of the references you quoted really are reflective of the Mustard, which is a lesson that we learned 20 years ago, that the risk of atrial arrhthymias and sinus node dysfunction is much more likely with the complete Mustard than with a full Senning.

And my final question is about the fundamental physiology of the 1.5-type repair. There is quite good evidence that the functional capacity of a 1.5-type physiology compared with a true biventricular repair is significantly different and that your exercise tolerance when you exercise these kids is not dissimilar to that of the Fontan circulation, and I think your group has quoted that in the past. You make a very good rationale in maybe a slightly small right ventricle or with the ability to delay conduit replacementbut if you've got a good-sized right ventricle, if you're doing a double switch rather than having to put a conduit in, and you've not got much in the way of tricuspid regurgitation, do you not think it would still be better doing a complete Senning than doing this 1.5-type approach?
Dr Malhotra. Well, I think this is where the interesting discussion comes in, because our patients certainly are very functional at midterm follow-up. And you are correct, we do have to go to the exercise lab and see how they do compared with Sennings. Nonetheless, we have found that the patients, from the feedback that we have gotten from their cardiologists, are doing very well. Our results demonstrate that they have excellent functional outcomes. LV function is preserved in over $85 \%$ of the patients. And like I said, it does help you technically in the operating room, also when you're dealing with these rotational anomalies in the midst of technically demanding operations with long ischemic times, to be able to do the simplified baffle and then do the bidirectional Glenn after the cross-clamp is removed helps your function as well. So it's a great question to go back and forth about, but I think we've developed our strategy for this very heterogeneous, challenging group of patients, and I would argue that I think we're fairly confident in how they have done at this point.

Dr Barron. I quite agree. I think you've shown us a very safe operation and you have outstanding results that it's difficult to argue with. My feeling is we shouldn't dismiss the Senning, because you've also shown you've had excellent results with the Senning and certainly I believe you get a better functional result with a full Senning.

Thank you very much, it's an excellent presentation.

Dr John E. Mayer, Jr (Boston, Mass). I just wanted to follow up a little bit on the heart block, because the technique you described of actually sewing the inferior vena cava to left atrial, effectively, left atrial baffle, is to sew right along the right $\mathrm{AV}$ valve annulus, which seems like it would be okay for L-transposition, but in the IDD patients where there is much more normal course of the conduction system it would seem as though your suture line would be crossing right over the arteriovenous node or the His bundle.

So the questions are: Is there any difference in your incidence of immediate postoperative heart block in the patients with IDD hearts as opposed to SLL hearts, and do you alter the technique in terms of how you sew your baffle in for the patients who have IDD anatomy?

Dr Malhotra. Well, we had 6 patients that had IDD anatomy, none of them developed postoperative heart block. So, I doubt that heart block is related to the Hemi-Mustard suture line. As we know, this is a group of patients at risk for heart block. In our series, four patients who came to us with heart block before-

Dr Meyer. I think we all understand that part.

Dr Malhotra. - the high risk of the natural history of L-transposition or congenitally corrected transposition. But no, we don't alter the baffle technique. 